EESTI NSV TEADUSTE AKADEEMIA TOIMETISED. VII KOIDE
BIOLOOGILINE SEERIA. 1958, NR. 3

ИЗВЕСТИЯ АКАДЕМИИ НАУК ЭСТОНСКОЙ ССР. ТОМ VII

СЕРИЯ БИОЛОГИЧЕСКАЯ. 1958, № 3

\title{
KARTULI FUTONEMATOODIDEST EESTIS MUGULATE TALVISE SÄILITAMISE PERIOODIL
}

\author{
E. KRALL
}

Kirjanduse andmeil hävib mitmesuguste haiguste tôttu Eestis igal aastal 15-18\% karlulisaagist, kusjuures kaod ulatuvad sageli kümnetesse tuhandetesse tonnidesse. Eriti rohkesti hukkub kartuleid talvisel säilitamisel (Marlandi (1956) andmeil 20-30\% salvestatud saagist). Peamisteks kahju tekitajateks on lehemädanik, varrepõletik ja mitmesugused viirushaigused. Märksa vähem tähelepanu on osutatud loomkahjuritele ja parasiitidele. Ometi leidub meil pinnases sageli esinevate nematoodide ehk ümmarusside klassi kuuluvate loomade hulgas terve rida liike, kes on kohanenud parasiteeriva eluviisiga taimekudedes. Nende seas esineb spetsiffilisi, ainult kartulile omaseid kahjureid, kes põhjustavad saagi tunduvat vähenemist.

Eestis kartulil parasiteerivatest nematoodidest on tähtsamad kartuli-kiduuss (Heterodera rostochiensis Woll.; avastati meil 1953. a.; esineb vaid üksikutes kolletes), kartuli-ingerjas (Ditylenchus destructor Thorne), ebaingerjas (Neotylenchus abulbosus Steiner) ja niiduingerjas (Pratylenchus pratensis d. M.). Peale nende esineb veel poolparasiitseid liike.

Kartulil parasiteerivate nematoodide íauna süstemaatilist uurimist Eestis alustati 1954. aastal. Vegetatsiooniperioodi jooksul vōeti proove kartuli juurtest, mugulatest, maapealsetest osadest ja juurte ümber olevast pinnasest. Talvisel säilitamisperioodil aga tehti analüüse hoidlatesse paigutatud mugulatega.

Käesolev artikkel käsitlebki kartulil esinevate nematoodide faunat põhiliselt kartuli säilitamise perioodil.

\section{Uurimismaterjal ja metoodika}

Uurimistöö pōhineb 200 kartulimugula detailsel analüüsil, mis teostati lehtrimeetodil. Analüüsilehtedel kirjeldatud mitmesuguste mädanike tunnustega kartulimugulad lõi. gati pärast pesemist tükkideks ja paigutati suurtesse klaaslehtritesse, mille otsa kinnitati Mohri näpitsaga suletav kummitoru. Lehtritesse valati vett, nii et mugulad olid üleni kaetud. Tavalises toatemperatuuris seistes väljusid nematoodid mugulatest ja langesid lehtrite põhja, kust pärast $6-12$ tunni möödumist vōeti igast $2-3 \mathrm{~cm}^{3}$-line vedelikuproov, mis fikseeriti formaliiniga ja analüüsiti binokulaari all tumedal väljal 16-32-kordsel suurendusel. Nematoodide vähese arvu puhul korjati nad kõik peenikese entomoloogilise nōela abil proovist välja. Erinevatel mugulate mädanemise staadiumidel esines sageli massiliselt saproobseid nematoode, kusjuures nende isendite arv mugulas vôis ulatuda kümnetesse tuhandetesse. Sellisel juhul piirduti kvalitatiivse analüüsiga, kusjuures korjati järjest välja 50-200 ettesattuvat nematoodi ning asetati nad uuriklaasidele glütseriini ja $96^{\circ}$ piirituse segusse (vahekorras 1:3). Mõne päeva kuni nädala jooksul toimus veetustamisprotsess, kusjuures nematoodid jäid pärast piirituse auramist glütseriini ja muutusid läbipaistvaks. Seejärel asetati nad nõela abil alus. 
klaasile sula glütseriin-želatiini tilga sisse ja kaeti õhukese (immersiooniga töötamist vōimaldava) katteklaasiga. Preparaadi jahtumisel kaeti selle ääred kuivamise vältimiseks kanada palsamiga või universaal-liimiga $* \mathrm{~B}_{2} \Phi$. Preparaatides määrati nematoodid, üle 6500 isendi.

\section{Uurimistulemused}

Talvisel säilitamisperioodil kahjustab kartulit Eesti NSV tingimustes kõige enam kartuli-inger jas (Ditylenchus destructor Thorne, 1945). Meie vabariigis täheldati tema kahjustusi esmakordselt 1953. aastal Tartus. Praeguste andmete järgi on ta vabariigi mandriosas laialt levinud kahjur (puuduvad veel andmed saartelt). Ingerja lai levikuala ning esinemine ka naaberaladel annab pōhjust oletusele, et ta on kahjustanud meil juba varasematelgi aastatel, tõenäoliselt isegi aastakümnete jooksul. NSV Liidus tehti ingerjas esmakordselt kindlaks 1932. aastal (Кирьянова, 1935), kusjuures teda leiti üheaegselt paljudes Euroopa-osa punktides. Uuematel andmetel on ingerjas põhjustanud kohati väga suurt kahju. Näiteks on Uknainas mõnedes majandites olnud nakatatud 30-40\% kõigist kartulimugulaist (Рысс, 1954), Armeenias on täheldatud kartuli kadu 8-30\% ulatuses (Погосян, 1954). Eestis ei ole seni andmeid kahjustuste ulatuse kohta süstemaatiliselt kogutud. Uksikud faktid aga näitavad, et meil talveperioodil kartulihoidlates 6-7\% mugulatest on olnud nakatatud kartuli-ingerjast (Кралль, 1957).

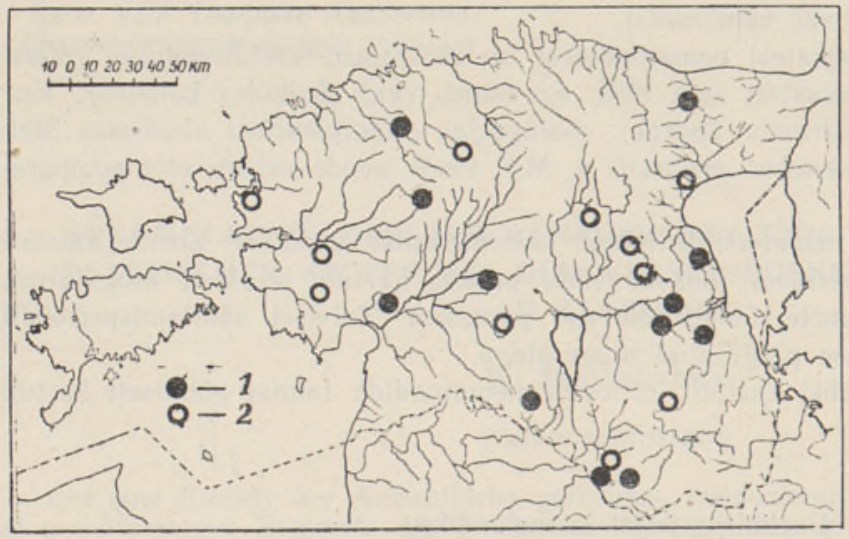

Joon. 1. Kartuli-ingerja ja ebaingerja senised leiukohad Eestis: 1 - Ditylenchus destructor Thorne, 2 - Neotylenchus abulbosus Steiner.
Kartuli-ingerja kahjustusi vổib meil märgata vihmastel suvedel, eriti niiskel maal. Ingerjas parasiteerib suvel kartulitaime maapealsetes osades, eriti varre alumises osas. Kui taim hakkab mugulaid moodustama, tungivad parasiidid sinna. Pärast sügisest saagi koristamist jääb osa ingerjaid koos kartulivarte ja haigete mugulatega ka mulda, kus nad järgmisel aastal na. katavad uusi kartulitaimi.

Kartuli-ingerja peamised kahjustused langevad talveperioodile, kus juures olulist osa etendab kartulihoidlate seisukord. Niisketes ja soojades keldrites paljunevad ingerjad väga intensiivselt ja nakatavad järjest uusi mugulaid. Säärane olukord kujuneb peamiselt kevadtalvisel säilitamisperioodil.

Kartuli-ingerjas on üheks mugulate $\mathrm{k} \mathrm{u} \mathrm{i} \mathrm{v} \mathrm{mä} \mathrm{d} \mathrm{a} \mathrm{n} \mathrm{i} \mathrm{ku} \mathrm{põhjustajaks.}$ Kahjustuse varasemas järgus muutub kartuli koor kahjustatud kohas värvuselt tinahalliks ja hakkab mugulast kergesti eralduma. Kahjustuse hilisemal etapil tekivad mugula pinnale lōhed ja praod (mikrofoto 1). See, et koor muutub järjest lahtisemaks ja kergesti eraldub, võimaldab vahet teha ingerjast põhjustatud kuivmädaniku ja mitmesugustest seen- 


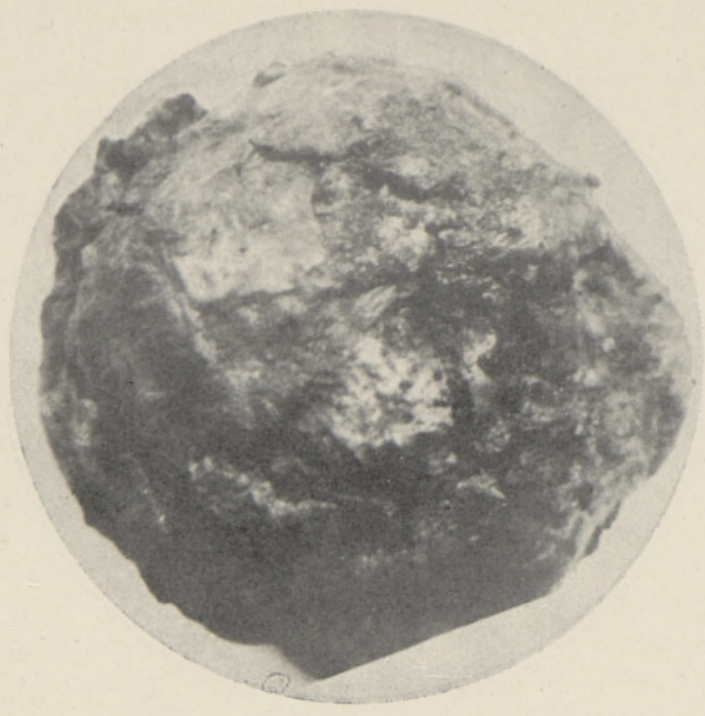

Mikrofoto 1. Kartuli-ingerja tekitatud kuivmädanikust tugevasti nakatatud mugul. Pinnale on tekkinud lōhed ja koor muutunud lahtiseks.

Микрофото 1. Клубень картофеля, сильно пораженный стеблевой нематодой.
Mikrophoto 1. Durch das Stengelälchen an der Kartoffelknolle hervorgerufene Trockenfäule.

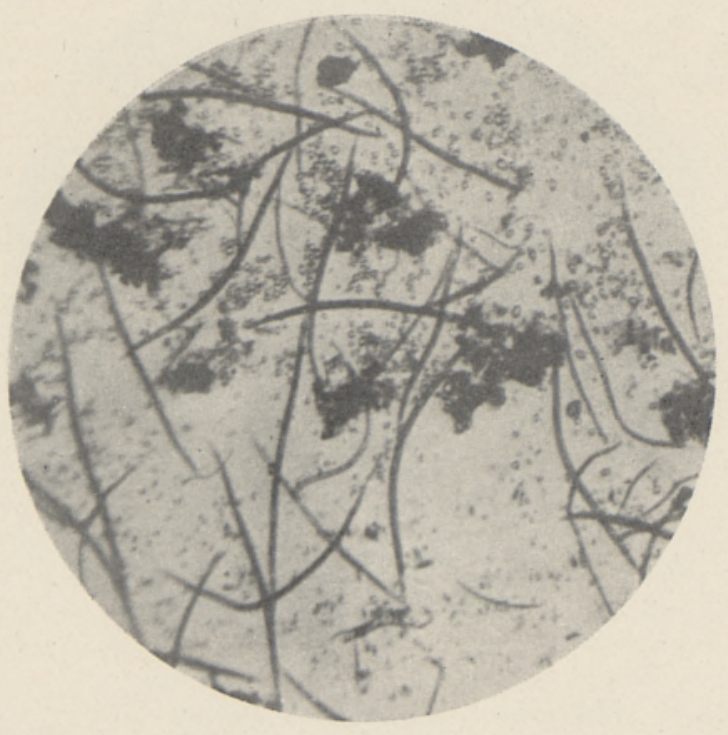

Mikrofoto 2. Kartuli-ingerja populatsioon mugulas. (Suurendus $25 \times$.)

Микрофото 2. Популяция стеблевой нематоды картофеля в клубне. (Увелич. $25 \times$.)
Mikrophoto 2. Eine Population des Stengelälchens in der Kartoffelknolle. (Vergrösserung $25 \times$.) 


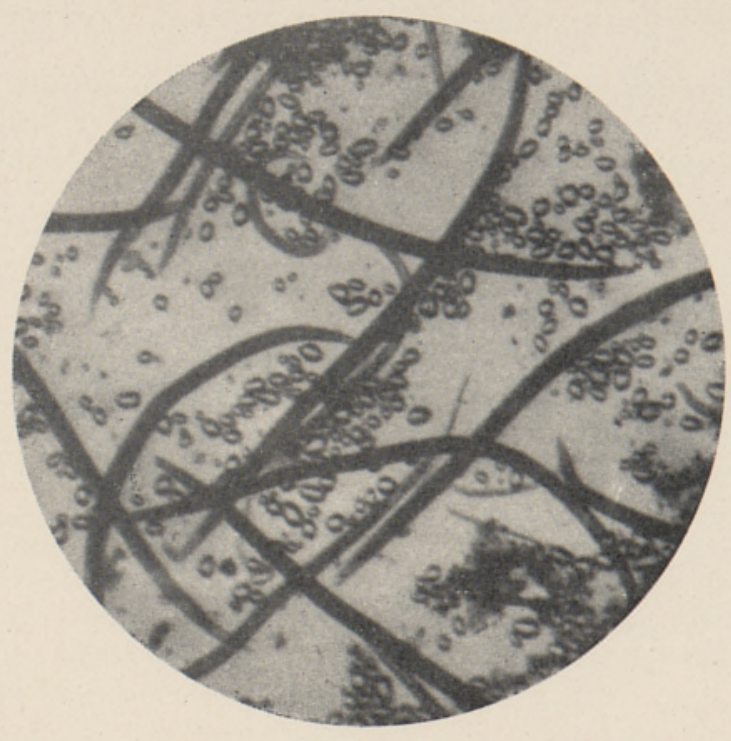

Mikrofoto 3. Kartuli-ingerja populatsioon mugulas. (Suurendus $50 \mathrm{X}$.)

Микрофото 3. Популяция стеблевой нематоды картофеля в клубне. (Увелич. $50 \times$.)
Mikrophoto 3. Eine Population des Stengelälchens in der Kartoffelknolle. (Vergrösserung $50 \times$.)

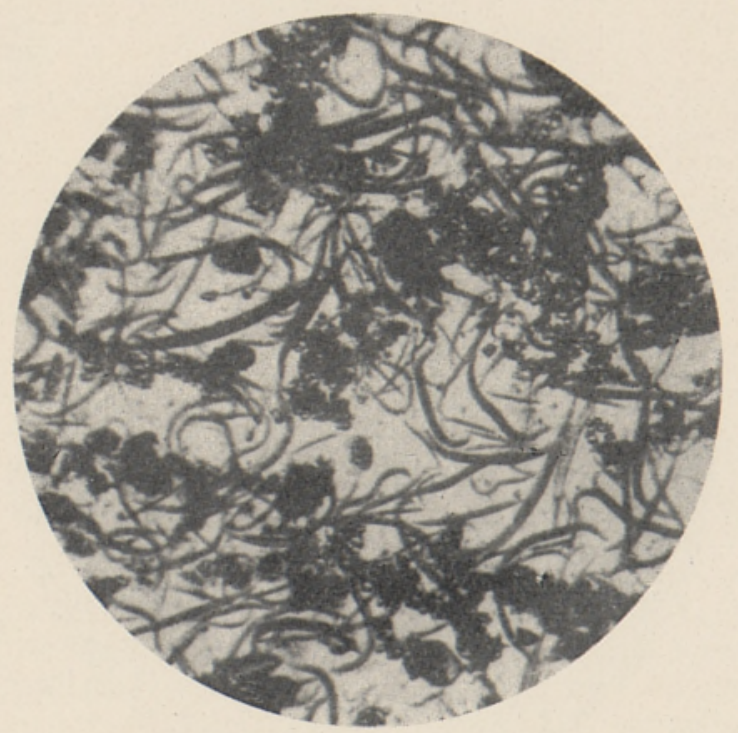

Mikrofoto 4. Saproobsete nematoodide massiline paljunemine kartulimugulas.

(Suurendus $25 \times$.)

Микрофото 4. Массовое размножение сапрозойных нематод в клубне картофеля. (Увелич. $25 \times$.)
Mikrophoto 4. Massenhafte Vermehrung der saprobiotischen Nematoden in der Kartoffelknolle. (Vergrös- 
haigustest esilekutsutud mädanike vahel (viimaste puhul on koor mugula küljes tavaliselt kinni). Seene Phylophtora poolt pōhjustatud mädaniku puhul levib kahjustus üksikute keeltena mugula pinnalt tema sisemusse (näha mugula läbilōikes). Mädanik on kõva konsistentsiga. Ingerjas aga levib enam-vähem ühtlaselt kogu koorealuse pinna ulatuses. Kahjustatud mugul on küll helepruuni värvusega, aga kobe ja kergesti pudenev.

Parasiteeriva eluviisi tõttu saavad ingerjad areneda ainult tervetes, kahjustamata mugulaosades, kusjuures nad paiknevad kahjustatud ja terve koe piiril. Kahjustuse laienedes migreeruvad ingerjad tervetesse mugulaosadesse ja seda niikaua, kuni kogu mugul on haaratud kuivmädanikust. Kartulihoidla tingimustes siirduvad ingerjad edasi naabruses asetsevatesse mugulatesse, kuna mädanikupiirkonda jäänud isendid hukkuvad.

Kuivmädanikust lagundatud kartulimugula viivad täielikule hävingule teised, nn. s a p ro o bs ed (mädanevas keskkonnas elavad) nematoodide liigid. Koos viimastega, osalt nende otsesel vahendusel tungivad kahjustatud mugulatesse mitmesugused bakterid ja seened. Seetõttu tekib mugulas mä r g mä da n i k - algul paiguti, hiljem kogu ulatuses. Lagunemisprotsesside kulg sealjuures on väga kiire ja lõpeb mugula täieliku hävimisega.

Analüüsitud materjalides võis korduvalt täheldada mitmesugusêid kartuli-ingerja kultuuri saproobsete liikide kultuuriks ülemineku faase. Tüüpilistel kuivmädanikujuhtudel esinesid ingerjad mugulas puhaskultuurina (mikrofotod 2 ja 3). Mädanemisprotsesside edasi arenedes vähenes nende arv pidevalt. Seevastu ilmusid mugulasse üksikud saproobsed nematoodid, kelle hulk ingerjate arvu vähenedes üha suurenes. Hilisemates, märgmädanikustaadiumides võis mugulais mõnikord leida veel üksikuid ingerjaid, kuna saproobsed liigid, kes olid jōudnud massiliselt paljuneda, olid domineerivad (mikrofoto 4). Uheks selliseks suktsessiooni käigus pärast ingerjat massiliselt paljunevaks saproobseks liigiks oli Diplogaster theritieri.

Ingerja järkjärguline taandumine mugulast, seoses muudatustega keskkonnas, raskendab tunduvalt tema patogeensuse ulatuse määramist kartulihoidlates, eriti kevadtalvisel säilitamisperioodil.

Teiseks talvisel säilitamisperioodil kartulimugulaid kahjustavaks liigiks on meil ebaingerjas (Neotylenchus abulbosus Steiner, 1931). 1939. aastal märkis Kirjanova (1939), et Eestist NSV Liitu saadetud kartul oli nakatatud ebaingerjast. Hilisemate uuringute andmeil on ka see liik Eestis laialt levinud. Ta põhjustab mugulates samasugust kuivmädanikku nagu ingerjaski. Ebaingerjas võib mugulates esineda samuti monokultuurina. Analüüsid näitasid, et ta mädanevas keskkonnas on mõnevõrra resistentsem kui kartuli-ingerjas.

Bioloogiliselt huvitavaks erinevuseks ingerja ja ebaingerja vahel on see, et viimases liigis esineb harva isasloomi (paljunemine toimub ilmselt partenogeneetiliselt), kuna ingerjal esinevad tavaliselt mõlemad sugupooled. Paramonov ja Haritškova (1953) käsitlevad ebaingerjat patogeensuse poolest mittespetsiifilise fütohelmindina; kartuli-ingerjaga võrreldes on ta palju vähem patogeenne. Kirjanova (1955) seevastu leiab, et ebaingerjas põhjustab samasugust kahju kui ingerjaski. Käesoleva uurimistöö käigus analüüsides ilmnes, et ebaingerjas esines sageli mugulates, mis avaldasid kartuli-ingerja kahjustuse tunnuseid.

Kartuli kuivmädanikuga kaasnesid real juhtudel veel mõned liigid närb-usside (Aphelenchoides) perekonnast. Osa selle perekonna liike on taimeparasiidid, osa aga elab vabalt pinnases. Kartulimugulais esines kaunis sageli $A$. parietinus't, keda tavaliselt peetakse poolparasiitseks, s. t. 
mitmesuguste seen- ja bakteriaalsete haigustega kaasnevaks liigiks. Meie arvates võib ta üksikjuhtudel, hulgalisema paljunemise korral, omada patogeenset tähtsust mädaniku tekitamisel. Samast perekonnast esinesid harvemini $A$. helophilus, $A$. tenuicaudatus ja $A$. limberi.

Uhel juhul täheldasime teise poolparasiitse liigi, Aphelenchus avenae Bast., massilist paljunemist kartulimugulas. Tavaliselt kaasneb see liik teatavais mädanemisprotsessi faasides saproobsete nematoodidega ja ei esine massiliselt.

Kartulimugulate imitteparasiitne fauna erineb talvisel säilitamisperioodil järsult kartulil esinevate nematoodide faunast suvise vegetatsiooniperioodi jooksul. Erinevused on nii kvalitatiivset kui ka kvantitatiivset laadi. Vegetatsiooniperioodil iseloomustab kartulimugulate nematofaunat pararisobiontide, s. t. selliste liikide olemasolu, kes elavad taimede juurte ümber ja tungivad mõnikord ka juurtesse, kuid osutuvad kahjulikuks vaid erandjuhtudel, koos teiste pōhjustega. Tervetesse mugulatesse säärased liigid tavaliselt üldse ei tungi, nagu tõendavad ka Meržejevskaja (1953) andmed. Nende faunat iseloomustab ühelt poolt rühmade Dorylaimoidea, Tylenchidae ja eriti Cephalobidae kvalitatiivne mitmekesisus ning teiselt poolt Rhabditinae ja Diplogasterinae suhteline piiratus.

Kartuli talvisel säilitamisel väheneb pararisobiontide arvukus märgatavalt:" Kartulihoidlates säilitatud mugulate külge jäänud mulla spetsiaalsed analüüsid näitasid, et nematoode seal harilikult enam ei esinenud. Neid ei leidunud ka tervetes mugulates ega külmumisest või seen(resp. bakter)haigustest põhjustatud mädanike algstaadiumides.

Järgnevalt vaatleme kartuli saproobset nematofaunat mugulate mädanemise viimastel staadiumidel, millal tavaliselt esineb juba märgmädanik.

Kartuli mädanemine on tingitud mitmesugustest põhjustest, sealhulgas ka patogeensetest nematoodidest. Mädanemise viimaseid staadiume iseloomustab tavaliselt massiline saproobsete nematoodide esinemine. Need aitavad oma eritustega ja patogeense mikrofloora aktiivsete inokuleerijatena kahtlematult kaasa mugulate lõplikule lagunemisele (Калиненко, 1936). Sellistes mugulates on rikkalikult esindatud mitmesugused liigid rühmadest Rhabditinae ja Diplogasterinae, kuna Dorylaimoidea ja vabaltelavate Tylenchidae esindajaid leidub vaid üksikjuhtudel. Cephalobidae esindajad, kuigi neid on mitu liiki, samuti regresseeruvad, sest nende populatsioonid on tavaliselt väiksearvulised (erandi moodustab mõnikord Panagrolaimus rigidus).

Mädanevate mugulate nematofaunas on otstarbekohane eristada esiteks tüüpilisi, mugulatele väga iseloomulikke liike; teiseks - esinemiselt vähem tüüpilise iseloomuga, kuid mugulas hästi kohanenud liike ja lōpuks - juhuslikke liike.

Kartulimugulate nematofauna tüüpilisust saagi talvise säilitamise tingimustes tuleb mõista relatiivselt, nimelt võrreldes mugulate talvist nematofaunat kartuli juurte, maapealsete osade, juurte ümber oleva pinnase ja lõpuks mugulate vegetatsiooniaegse nematofaunaga.

Teisest küljest on vaja silmas pidada, et erinevatel mädanemisstaadiumidel prevaleerivad mugulates erinevad nematoodide liigid. Tüüpilised on neist sellised, mis on hästi kohanenud antud staadiumi tingimustega. Kuna väliskeskkonna muutumisel üksikute liikide teistega asendumise detailsed seaduspärasused on veel tundmata, võib iseloomulikest liikidest kõnelda vaid kõige üldisemates joontes (summeerides kõigi staadiumide fauna).

Eusaprobiontide eluvormist (Paramonovi (1952) terminoloogia) on mädanevates kartulimugulates väga tüüpilised Diplogaster lheritieri, D. superbus, Rhabditis brevispina, Rh. teres, Rh. aspera, Rh. pseudo- 
xycerca, Rh. curvicaudata ja teised nendesse perekondadesse kuuluvad liigid, ning Cheilobus quadrilabiatus; devisaprobiontidest - Panagrolaimus rigidus. Neile kõigile on omane väga intensiivne paljunemine mugulates. Nende kōrval vôib eristada teise rühma kuuluvaid liike, selliseid, kes mugulates samuti hästi on kohanenud, kuid siginevad visamalt, nagu Diplogaster (Eudiplogaster) striatus, Cephalobus persegnis, Eucephalobus striatus, Plectus granulosus ja poolparasiitidest Aphelenchus avenae. Juhuslike liikidena vỗib nimetada tavalisi pinnasenematoode (pararisobionte), keda esineb mugulates harva ning üksikute isenditena ja kelle toime mugulątesse ei oma seetõttu märkimisväärset tähtsust. Siia kuuluvad: Alaimus primitivus, Dorylaimus bastiani, Dorylaimus obtusicaudatus, Eucephalobus oxyuroides, Eucephalobus elongatus, samuti liigid perekondadest Tylenchus, Tylenchorhynchus, Acrobeloides jt.

Tuleb oletada, et üksikud mugulate rühmad või isegi üksikud mugulad moodustavad ühe kartulihoidla piirides iseseisva, oma tsönoosiga «mikrobiotoobi». Niisugusei juhul esineb antud nematoodiliigil palju populatsioone, millest annab tunnistust mugulate mädanemine kolletena. Loomulikult leiab hoidlatingimustes aset fauna segunemine: toimuvad nematoodide migratsioonid ïhest mugulast teise. Kuid intensiivne paljunemine toimub jällegi teises mugulas, nii et väike invasioon (mõni isend) võib teatava aja jooksul anda uue populatsiooni, kui tingimused teises mugulas on soodsad. Tingimuste muutumisel ebasoodsaks, mida osalt põhjustab antud liigi enese elutegevus, toimub populatsiooni hukkumine ning mugula asustamine uue liigiga (resp. liikide kompleksiga). Väärib tähelepanu, et kaugelearenenud mädanike puhul on mugulad sageli samaaegselt asustatud peamiselt ühe nematoodiliigi indiviididega.

\section{KIRJANDUS}

Marland, A., 1956. Rohkem tähelepanu taimekaitsele meie vabariigis. «Eesti Kommunist», nr. 4.

К ал ин енко В. И., 1936. Инокуляция. нематодами патогенной микрофлоры в ткани каучуконосов. Материалы к Всесоюзному совещ. по изуч. нематод. М.-Л.

К и р в я н в а Е. С., 1935. Нематоды с.-хоз. растений западной полосы СССР. Паразитол. сб. Зоолог. ин-та АН СССР, V.

К и р в я н в а Е. С., 1939. Обзор изученности нематодных болезней растений в СССР. Сб. работ по нематодам с.-хоз. растеннй. Л.

К и р в я н о в а Е. С., 1955. Круглые черви - паразиты растений. Изд. АН СССР. М.-Л.

К ра лль Э. Л., 1957. К фауне фитонематод картофельных хранилищ Эстонской ССР. Тезисы докл. 1 научно-коорд. совещ. по паразитол. пробл. Литовской, Латвнйской, Эстонской и Белорусской ССР. Вильнюс.

М ер же е в ск а я О. И., 1953. Нематоды главнейших полевых культур БССР. Минск.

Гі а р а монов А. А., 1952. Опыт экологической классификацин фитонематод. Труды гельминтол. лаб. АН СССР, VI.

П а р а монов А. А. и Х а ри ч ко в а М. В., 1953. Возбудители фитогельминтозов картофельных клубней и лука в Московской области. Тр. Всесоюз. ин-та гельминт. им. акад. К. И. Скрябина, V.

Го огосян Э. Е., 1954. Паразитические нематоды картофеля Армянской ССР и разработка мер борьбы с ними. Нематодные болезни с.-хоз. культур. М.

Р ы с с Р. Г., 1954. Некоторые данные по биологии стеблевой нематоды картофеля и мерам борьбы с ней. Нематодные болезни с.-хоз. культур. М. 


\section{О ФИТОНЕМАТОДАХ КАРТОФЕЛЯ В ЭСТОНИИ В ПЕРИОД ЗИМНЕГО ХРАНЕНИЯ КЛУБНЕИ}

\section{Э. Л. Кралль}

\section{Резюме}

Наряду с другими возбудителями болезней, культуре картофеля в Эстонии вредят и некоторые фитопаразитические нематоды. В вегетационный период имеет значение картофельная нематода Heterodera rostochiensis Woll., отдельные очаги которой в республике обнаружены начиная с 1953 г., и ряд других видов.

Что касается стеблевой нематоды картофеля (Ditylenchus destructor Thorne), то этот вид имеет наибольшее практическое значение в период зимнего хранения клуб. ней. По имеющимся данным, в отдельных случаях заражение клубней стеблевой нематодой достигает от 6 до $7 \%$.

Кроме стеблевой нематоды, возбудителем сухой гнили картофеля является широко распространенная и в Эстонии ложностеблевая нематода (Neotylenchus abulbosus Steiner). Биологически интересно, что самцы ложностеблевой нематоды встречаются крайне редко, у стеблевой нематоды же они встречаются очень часто.

В последних стадиях гниения клубней, вызванного нематодами, картина повреждения представляет собой комбинацию повреждений, вызванных разными грибными и бактериальными заболеваниями. Поскольку стеблевая нематода (микрофото 2 и 3) не способна жить в сапробиотической среде, она или мигрирует в здоровые клубни, или погибает. Поврежденные клубни охватываются различными видами сапрозойных нематод. В нашем материале, например, можно было заметить замену популяции стеблевой нематоды популяцией сапрозойного вида Diplogaster lheritieri. Вытеснение стеблевой нематоды в последних стадиях гниения затрудняет определение объема действительного патогенного значения этого вида.

Фауна нематод клубней в зимний период отличается от их фауны в летний вегетационный период как в качественном, так и в количественном отношении.

Часто сапрозойные нематоды массово размножаются в клубнях (микрофото 4). Из эусапробионтов (Парамонов, 1952) для гнилых клубней типичными являются различные представители родов Rhabditis, Diplogaster и Cheilobus, напр. Rh. brevispina, $R h$. teres, Rh. aspera, Rh. pseudoxycerca, Rh. curvicaudata, D. Lheritieri, D. superbus и другие виды, Из девисапробионтов сюда входит Panagrolaimus rigidus.

Менее характерными для клубней, но все же хорошо приспособленными для жизни в последних являются Cephalobus persegnis, Eucephalobus striatus, Plectus granulosus, Aphelenchus avenae и др.

В качестве случайных для клубней рассматриваются обычные обитатели почвы, встречающиеся иногда в них в виде единичных экземпляров и не имеющие поэтому практического значения для клубней. Сюда входят: Dorylaimus bastiani, Dorylaimus obtusicaudatus, Eucephalobus oxyuroides, Eucephalobus elongatus, нематоды из родов: Tylenchus, Tylenchorhynchus, Acrobeloides и др.

Институт зоологии и ботаники Академии наук Эстонской ССР
Поступила в редакцню

8 II 1958 


\section{PHYTONEMATODEN DER KARTOFFEL WÄHREND DER LAGERUNGSPERIODE IN ESTLAND}

\section{E. Krall}

\section{Zusammenfassung}

Neben anderen Krankheitserregern werden die Kartoffelerträge in Estland durch verschiedene Nematodenarten beeinträchtigt. So können während der Freilandperiode Verluste durch den Kartoffelnematoden Heterodera rostochiensis Woll. verursacht werden, der in Estland seit 1953 bekannt ist, bisher aber nur in einzelnen Herden vorkommt.

Was das Stengelälchen (Ditylenchus destructor Thorne) anbetrifft, so sind durch diese Art hervorgerufene Schädigungen besonders während der Lagerungsperiode auffallend. Nach vorhandenen Angaben sind in Estland stellenweise 6-7\% der eingelagerten Kartoffeln durch das Stengelälchen befalien worden. Die befallenen Knollen zeichnen sich durch die Entwicklung einer spezifischen Trockenfäule aus (Mikrophoto 1).

Auch eine andere, in Estland weit verbreitete Nematodenart, Neotylenchus abulbosus Steiner, scheint imstande zu sein, an den Knollen Trockenfäule hervorzurufen.

Es ist biologisch bemerkenswert, dass die Männchen bei Neotylenchus abulbosus nur äusserst selten vorkommen, während sie bei Ditylenchus destructor sehr häufig sind.

In den letzten Stadien der durch Nematoden hervorgerufenen Fäule kombiniert sich das Schädigungsbild mit der durch verschiedene bakterielle und Pilzerkrankungen hervorgerufenen Nassfäule. Da das Stengelälchen als parasitische Form (Mikrophotos 2 und 3) nicht imstand ist, in einer saprobiotischen Umgebung zu existieren, muss sie entweder in gesunde Knollen migrieren oder umkommen. Die beschädigten Knollen werden nunmehr durch saprobiotische Nematodenarten befallen. Es ist uns gelungen, verschiedene Ubergangsstadien von eineP reinen Stengelälchenkultur bis zur Prävalierung einer saprobiotischen Fauna zu beobachten. Nicht selten konnte Diplogaster lheritieri als eine von diesen vikariierenden saprobiotischen Arten festgestellt werden. Durch das Verdrängen des Stengelälchens in den letzten Stadien der Fäulnisprozesse wird die Bestimmung der wirklichen patogenen Bedeutung dieser Art erschwert.

Im Vergleich mit der Knollenfauna im Sommer weist die Nematodenfauna der eingebrachten Kartoffel eigene qualitative und quantitative Unterschiede auf.

Die saprobiotischen Nematoden vermehren sich in den Knollen oft massenhaft (Mikrophoto 4). Von den Eusaprobionten (Paramonov, 1952) werden verschiedene Vertreter der Gattungen Rhabditis, Diplogaster und Cheilobus für die faulenden Knollen als typisch angedeutet. Hierzu gehören z. B. Rh. brevispina, Rh. teres, Rh. aspera, Rh. pseudoxycerca, Rh. curvicaudata, D. Lheritieri, D. superbus und andere Arten. Von den Devisaprobionten wird auch Panagrolaimus rigidlis zu dieser Gruppe gezählt.

Für die Knollen weniger charakteristisch, dennoch aber dem Leben in den Knollen gut angepasst sind Cephalobus persegnis, Eucephalobus striatus, Plectus granulosus, Aphelenchus avenae u. a.

Als zufällig sind einige Erdnematoden aufzufassen, die in den Knollen vereinzelt vorkommen und deshalb in bezug auf dieselben keine praktische Bedeutung haben können. Hierzu gehören: Dorylaimus bastiani, Dorylaimus obtusicaudatus, Eucephalobus oxyuroides, Eucephalobus elongatus, Nematoden aus den Gattungen Tylenchus, Tylenchorhynchus, Acrobeloides usw.

Institut für Zoologie und Botanik

der Akademie der Wissenschaften der Estnischen SSR
Eingegangen

am 8. Febr. 1958 